\title{
A New Laccase Based Biosensor for Tartrazine
}

\author{
Siti Zulaikha Mazlan ${ }^{1}$, Yook Heng Lee ${ }^{1}$ and Sharina Abu Hanifah ${ }^{1,2, *}$ \\ 1 School of Chemical Sciences and Food Technology, Faculty of Science and Technology, Universiti \\ Kebangsaan Malaysia, Bangi, Selangor 43600, Malaysia; ieykamazlan58@gmail.com (S.Z.M.); \\ leeyookheng@yahoo.co.uk (Y.H.L.) \\ 2 Polymer Research Center, Faculty of Science and Technology, Universiti Kebangsaan Malaysia, \\ Bangi, Selangor 43600, Malaysia \\ * Correspondence: sharina@ukm.edu.my; Tel.: +603-8921-3902
}

Received: 4 October 2017; Accepted: 30 November 2017; Published: 9 December 2017

\begin{abstract}
Laccase enzyme, a commonly used enzyme for the construction of biosensors for phenolic compounds was used for the first time to develop a new biosensor for the determination of the azo-dye tartrazine. The electrochemical biosensor was based on the immobilization of laccase on functionalized methacrylate-acrylate microspheres. The biosensor membrane is a composite of the laccase conjugated microspheres and gold nanoparticles (AuNPs) coated on a carbon-paste screen-printed electrode. The reaction involving tartrazine can be catalyzed by laccase enzyme, where the current change was measured by differential pulse voltammetry (DPV) at $1.1 \mathrm{~V}$. The anodic peak current was linear within the tartrazine concentration range of 0.2 to $14 \mu \mathrm{M}\left(R^{2}=0.979\right)$ and the detection limit was $0.04 \mu \mathrm{M}$. Common food ingredients or additives such as glucose, sucrose, ascorbic acid, phenol and sunset yellow did not interfere with the biosensor response. Furthermore, the biosensor response was stable up to 30 days of storage period at $4{ }^{\circ} \mathrm{C}$. Foods and beverage were used as real samples for the biosensor validation. The biosensor response to tartrazine showed no significant difference with a standard HPLC method for tartrazine analysis.
\end{abstract}

Keywords: tartrazine; methacrylate-acrylate microspheres; AuNPs; electrochemical sensor; enzymatic biosensor

\section{Introduction}

Laccase (polyphenoloxidase; EC 1.10.3.2) is a well-known enzyme for the oxidization of a wide range of compounds such as polyphenols, methoxy-substituted phenols and diamines. This enzyme, which belongs to the blue multi-copper-oxidase family undergoes typical reactions where a phenolic group is often oxidised via one electron transfer to form a phenoxyl free radical. This results in an active oxygen species that could yield a quinone or further undergo polymerisation of the free radical. The ability of laccase to react with phenolic compounds opens up many opportunities of applications in agricultural, food, industrial, medical and environmental sectors [1].

Laccase based voltammetric/amperometric biosensors have been developed for food and beverages analyses. These biosensors have found wide applications in the analysis of phenol, polyphenol, guaiacol, gallic acid, caffeic acid, catechin, catechol, hydroquinone and resorcinol to name a few in various food and beverage products [2-4]. However, such biosensors have not been explored for food colour additives such as tartrazine. The selection of a suitable matrix for laccase enzyme immobilization in the construction of a biosensor for food analysis is a crucial part of the fabrication process [5]. The enzyme laccase immobilisation methods for the construction of biosensors reported for food analysis were based on several procedures involving laccase adsorptions (e.g., in carbon/graphite materials, nafion nanocomposite and screen-printed gold); enzyme entrapments (e.g., in polyazetidine prepolymer, chitosan, MWCNTs, PVA photopolymer and sonogel), enzyme 
cross-linkings (e.g., with cyanuric chloride/chitosan, polyvinylpropylidone gel, glutaradehyde on glassy carbon) and laccase covalent attachments (e.g., on nickel nanoparticles/MWCNTs/PANI, DEAE cellulose, ITO-APTES monolayer, glutaradehyde-cysteamine monolayer, magnetic nanoparticles or copper nanoparticles composite with MWCNTs and PANI) [6].

Polymeric microspheres are favourable materials for enzyme immobilization due to their high surface area in 3D shape, chemical stability, porosity and functional group density that can easily be tailored in accordance to their specific needs [7]. The poly(glycidyl methacrylate) (PGMA) containing epoxy group has been widely applied due to its attractive properties and discovered as an ideal support for enzyme immobilization [8]. They have the ability to form strong linkages with amino, hydroxyl, and thiols group under mild conditions $[9,10]$. The modifications of the epoxy ring with amine groups endow PGMA with excellent affinity to a variety of proteins, which makes it applicable in many areas, and easily available for immobilization of the enzyme [11]. The use of methacrylic based polymers in the forms of microspheres or cryogels for the immobilization of laccase have been reported with the aim of application to bioremediation and waste water treatment [12,13].

This study highlights the development of a new tartrazine biosensor based on laccase. To the best of our knowledge, detection of tartrazine catalyzed by laccase using the electrochemical biosensor technique has not yet to be reported. Tartrazine (Figure S1) is a synthetic organic food dye found in common food products such as beverages, candies, dairy products and bakery products [2]. However, the content of tartrazine must be controlled due to its potential harm to human beings, contributed from the azo groups $(\mathrm{N}=\mathrm{N})$ and aromatic ring structures [14]. In China, the permitted maximum limit of tartrazine additive in foods is $0.1 \mathrm{~g} / \mathrm{kg}$ (individually or in combination [2]. Tartrazine will cause many adverse health effects such as allergies, migraines, eczema, anxiety, diarrhoea and childhood hyperactivity if they are excessively consumed [15]. Therefore, convenient, rapid and reliable methods for rapid determination of tartrazine are essential for the food safety assurance. Traditionally, tartrazine has been analysed using spectrophotometry [3], chromatography [4], mass spectrometry-chromatography [5], capillary electrophoresis [16] and electrochemical methods using various chemically modified electrodes [17].

In this work, laccase enzyme was immobilized on poly(glycidyl methacrylate-co-n-butyl acrylate) (poly(GMA-co-nBA)) microspheres, which we have reported recently [18]. Poly (n-butyl acrylate) has a hydrophobic property and thus the microspheres are hydrophobic where the laccase immobilization will be confined to the surface of the spheres; this allows the enzymatic reaction with tartrazine to occur at the surface and diffusion limitation within the polymer matrix is eliminated [7]. Thus, we have attempted for the first time to utilize laccase enzyme for the successful construction of a biosensor for tartrazine analysis.

\section{Materials and Methods}

\subsection{Chemicals}

Cyclic voltammetry (CV) and differential pulse voltammetry (DPV) experiments were performed with AutolabPGSTAT 12 (Autolab, Metrohm, Zofingen, Switzerland) potentiostat. The parameters used for $\mathrm{CV}$ were $0.007 \mathrm{~V}$ for step potential and $0.05 \mathrm{~V} / \mathrm{s}$ of scan rate from -1.25 to $0.75 \mathrm{~V}$. For DPV, the parameters used were $0.02 \mathrm{~V}$ step potential in the scan range of -1.0 to $-0.1 \mathrm{~V}$. A screen printed electrode (SPE) supplied by Scrint Technology (M) Sdn. Bhd. coated with methacrylate-acrylate microspheres in the presence of gold nanoparticles (AuNPs) was used as working electrode. A rod-shaped glassy carbon electrode and $\mathrm{Ag} / \mathrm{AgCl}$ electrode were used as auxiliary and reference electrodes, respectively, and the $\mathrm{KCl}$ solution of 3.0 M was used as the internal solution of the $\mathrm{Ag} / \mathrm{AgCl}$ electrode. All potentials measured in this study were referred to $\mathrm{Ag} / \mathrm{AgCl}$ electrode and homogeneous mixture of material solutions was prepared using sonicator bath Elma $\mathrm{S} 30 \mathrm{H}$.

The following chemicals were obtained from commercial sources: glycidyl methacrylate, GMA (Sigma-Aldrich, St. Louis, MO, USA), n-butyl acrylate, nBA (Merck, Kenilworth, NJ, USA), ethylene 
glycol dimethacrylate, EGDMA (Sigma-Aldrich, St. Louis, MO, USA), sodium dodecyl sulphate, SDS (Systerm), 2,2-dimethoxy-2-phenylacetophenone, DMPP (Sigma-Aldrich, St. Louis, MO, USA), glutaric aldehyde, GA (Sigma-Aldrich, St. Louis, MO, USA), Bradford reagent (Sigma-Aldrich, St. Louis, MO, USA) and bovine serum albumin, BSA (Sigma-Aldrich, St. Louis, MO, USA). Deionized water was used for preparing aqueous solution during experiments.

\subsection{Fabrication of Functionalized Microspheres and Electrochemical Characterization}

Colloidal AuNPs ( $<100 \mathrm{~nm}$ particle size) was purchased commercially. About $1 \mathrm{~g}$ of methacrylate-acrylate microspheres were added to $10 \mathrm{~mL}$ enzyme solution and kept at $4{ }^{\circ} \mathrm{C}$ for $24 \mathrm{~h}$ in order to immobilize the enzyme onto the microspheres. The SPE working electrode (AuNPs/SPE) was prepared by depositing AuNPs onto SPE and dried at room temperature. Then, methacrylate-acrylate microspheres immobilized with laccase enzyme was suspended in 90:10 of ethanol to water before being deposited onto the AuNPs/SPE. It refers as microspheres-laccase/AuNPs/SPE and dried at room temperature. The response of tartrazine biosensor was later examined with CV and DPV in $0.05 \mu \mathrm{M}$ phosphate buffer $\mathrm{pH}$ 5.0. Four SPEs were selected and fabricated including (a) bare SPE, (b) Laccase/SPE, (c) microspheres-laccase/SPE and (d) microspheres-laccase/AuNPs/SPE respectively. Electrochemical investigation of tartrazine was carried out in an electrochemical cell containing $4 \mathrm{~mL}$ of $0.1 \mathrm{M}$ PBS ( $\mathrm{pH}=5.0$ ) and $0.5 \mu \mathrm{M}$ of TT. The potential range was 0.50 to $1.30 \mathrm{~V}$ using microspheres-laccase/AuNPs/SPE as working electrode, a glassy carbon counter electrode and $\mathrm{Ag} / \mathrm{AgCl}$ reference electrode.

\subsection{Optimization and Evaluation of Electrochemical Tartrazine Biosensor}

The response of tartrazine biosensor was examined based on the effect of various parameters on the immobilized laccase. The influence of $\mathrm{pH}$ was analysed by varying $\mathrm{pH}$ of tartrazine solution that was prepared in $0.05 \mathrm{M}$ sodium phosphate in the $\mathrm{pH}$ range 2.0-8.0 [19]. The exposure time, which is the duration of the exposure of the electrode to tartrazine, could affect the optimum biosensor response. For this study, the exposure time was performed from 1-15 min before measurement. The procedure was carried using a different amount of AuNPs between $0.02 \mathrm{mg}$ and $0.10 \mathrm{mg}$. The microspheres amounts were also optimized. Effect of laccase concentration on biosensor response was also examined by varying laccase concentration over the range of $1.0-3.0 \mathrm{mg} / \mathrm{mL}$. The voltammograms were recorded from +0.60 to $+1.20 \mathrm{~V}$ at $0.07 \mathrm{~V} \cdot \mathrm{s}^{-1}$ scan rate. Under optimum conditions, DPV measurements were recorded from +0.60 to $+1.20 \mathrm{~V}$ to obtain the linear range and low detection limit of tartrazine biosensor. Furthermore, to evaluate the interference that may interfere on the tartrazine determination, tartrazine concentration is fixed at $0.5 \mu \mathrm{M}$. Then, the interferences were added with various ratios of concentration. Other performances of biosensor including reproducibility and repeatability were also examined using DPV. Stability studies were carried out by storing electrode at $4{ }^{\circ} \mathrm{C}$ for 90 days. The electrode was immersed in $0.1 \mathrm{M}$ PBS $(\mathrm{pH}=5.0)$ when it was not in use. The electrode performance was checked daily using DPV [20,21].

\subsection{Determination of Tartrazine in Food Samples}

The samples were purchased from a local market. All simultaneous determinations of each sample were performed by standard addition method and have been repeated 3 times under the same conditions to examine and to improve the results' accuracy. For electrochemical analysis, $20.0 \mathrm{~mL}$ commercial mango juice or $20.0 \mathrm{~g}$ candy coated chocolate was taken and dissolved in $20 \mathrm{~mL} 0.1 \mathrm{M}$ PBS ( $\mathrm{pH}$ 5.0). The synthetic dye content in commercial mango juice was determined by the standard addition method to prevent any matrix influence.

\subsection{Validation and Recovery Studies of Tartrazine in Food Samples}

Samples were also validated and analysed by high performance liquid chromatography (HPLC). HPLC system consisted of a binary pump, a degasser, an automated injector, a column oven and 
an UV-vis detector (Agilent 1100 Series HPLC, Agilent Technologies, Massachusetts, USA). HPLC was also introduced to detect tartrazine in drinks according to Alves et al. [22]. The column was a C18 analytical column $(4.6 \mathrm{~mm} \times 250 \mathrm{~mm} \times 5 \mu \mathrm{m})$. One mobile phase system was employed to accomplish a quick separation of the analysed dyes in samples. It contained methanol (solution A) and $0.08 \mathrm{~mol} \cdot \mathrm{L}^{-1}$ aqueous ammonium acetate (solution B). Prior to usage, the aqueous solution and methanol were further filtered through $0.45 \mu \mathrm{m}$ membranes. A constant flow rate was $0.7 \mathrm{~mL} \cdot \mathrm{min}^{-1}$ and the injection column was $20 \mathrm{~mL}$. After completing the chromatographic elution, the mobile phase was programmed to its initial condition within $5 \mathrm{~min}$, while $10 \mathrm{~min}$ reconditioning time was set before next injection. The detection was performed at a wavelength of $417 \mathrm{~nm}$ for both sunset yellow and tartrazine with UV-vis spectra detector. Statistical analysis (Student $t$-test) was performed by Microsoft Excel datasheets for comparison of both techniques.

\section{Results}

\subsection{Methacrylate-Acrylate Microspheres}

Surface morphology of methacrylate-acrylate microspheres was characterized by SEM and as presented in Figure S2A. The micrographs revealed that the synthesized copolymers were in spherical shape. However, when nBA composition was increased from $10 \%$ to $20 \%$, the microspheres tended to be more aggregated, as exhibited by the micrograph (Figure S2D). This may be explained via a higher quantity of nBA that leads to the merging of the monomer into larger droplets; hence, an increase in the size of the microspheres formed after photopolymerization. The increase of sticky properties is caused by nBA [23]. The particle size of microspheres were then determined in Figure S2E. Copolymer of GN91 obtained the highest percentage of microspheres diameter in the range of 0.1 to $2.0 \mu \mathrm{m}$ for GN91 copolymer compared to 1.0 to $4.0 \mu \mathrm{m}$ for GN82. As a result, the total surface area of reaction will be increased and improved enzyme binding onto the polymer microspheres will occur, as reported by Ling and Heng (2010).

\subsection{Electrochemical Behaviours of Tartrazine}

Theoretically, tartrazine catalysed by laccase will produce a non-reversible reaction. As presented in Figure 1, there were different electrochemical behaviours revealed on (a) bare SPE (b) laccase/SPE, (c) microspheres-laccase/SPE and (d) microspheres-laccase/AuNPs/SPE. The electrochemical properties of tartrazine on the different carbon paste screen printed electrodes (SPE) were studied using cyclic voltammetry (CV). Figure 1 shows the electrochemical behaviour of $0.5 \mu \mathrm{M}$ tartrazine. Bare SPE (a) confirmed that neither oxidation nor reduction peak was observed. In contrast, the oxidation peak of tartrazine increases significantly when both of the microspheres and AuNPs used simultaneously, as compared to 1(b) and 1(c). At the microspheres-laccase/SPE, tartrazine produced a small peak. This can be ascribed to poor conductivity and small effective surface area of reaction of modified electrode (curve c). Based on the inset voltammograms in Figure 1, the anodic peak current that refers to oxidation of tartrazine for electrode functionalized AuNPs and microspheres was much higher than the electrode without microspheres. This indicates that microspheres can increase the surface area of reaction in this system because many more enzymes could be immobilized on a larger surface area. It is well known that spheres have the largest surface to volume ratio so that in a small space, the area is the largest and this favours more enzyme immobilization.

This biosensor system needs microspheres since microspheres are covalently bound with laccase enzyme. Microspheres act as a surface of reaction for laccase and the analyte, tartrazine. Although the non-conductive polymeric microspheres were used, the electron transfer can happen via AuNPs towards the carbon SPE. The electron transfer depends strongly on the immobilization procedure. This is due to the distance between the prosthetic group of the enzyme and the fact that the electrode surface is often rather long for direct electron transfer [24]. To overcome its limitation that leads to the unfavourable conditions for electron transfer, an optimally designed electrode configuration has to 
ensure that the electron transfer distance between an immobilized enzyme and electrode surface is made as short as possible or conductive material such as AuNPs is added. AuNPs act as tunnels for electron transfer on SPE electrodes. The tunneling effect of AuNPs allow the electron with less energy to tunnel through the barrier and be detected by the transducer. These results prove that the SPE electrode surface coating with microspheres of methacrylate-acrylate-AuNPs can improve the efficiency of the electrode surface area of reaction (Sharma et al. 2008). After the introduction of methacrylate-acrylate microspheres-AuNPs on the SPE, tartrazine exhibited only an anodic peak at Figure 1d about $+1.1 \mathrm{~V}$, revealing that tartrazine underwent a totally irreversible process, while the cathodic peak at $0.67 \mathrm{~V}$ refers to oxidation of $\mathrm{AuOH}$ to $\mathrm{Au}$ [25]. At the microspheres-laccase/AuNPs/SPE (curve d), the peak current of tartrazine increased dramatically and the background was larger than that of microspheres-laccase/SPE, meaning that AuNPs can significantly enhance the current response.

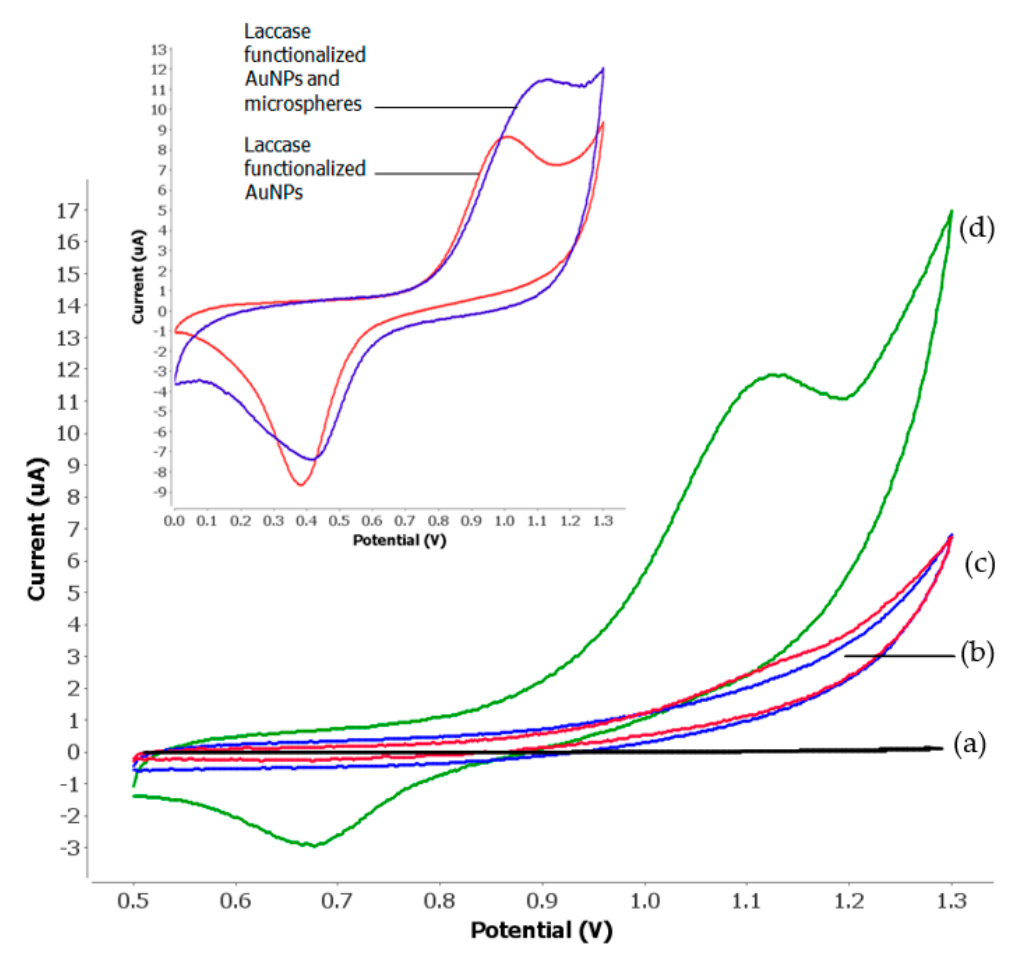

Figure 1. Cyclic voltammograms of (a) bare SPE, (b) Laccase/SPE, (c) microspheres-laccase/SPE and (d) microspheres-laccase/AuNPs/SPE in the presence of $0.5 \mu \mathrm{M}$ Tartrazine in 0.1 M PBS pH 5.0. Scan rate: $0.07 \mathrm{~V} / \mathrm{s}$. A magnified view of the comparison between AuNP-only (red) and AuNP/microspheres (blue) electrodes voltammogram is shown at the inset.

Overall, tartrazine has an oxidation peak at $1.1 \mathrm{~V}$. In the presence of the enzyme laccase, it helps to catalyze tartrazine to the oxidation state on the surface of the microspheres-laccase/AuNPs/SPE modified electrode through an electron transfer. Scheme 1 shows the proposed electrochemical process catalyzed by laccase.

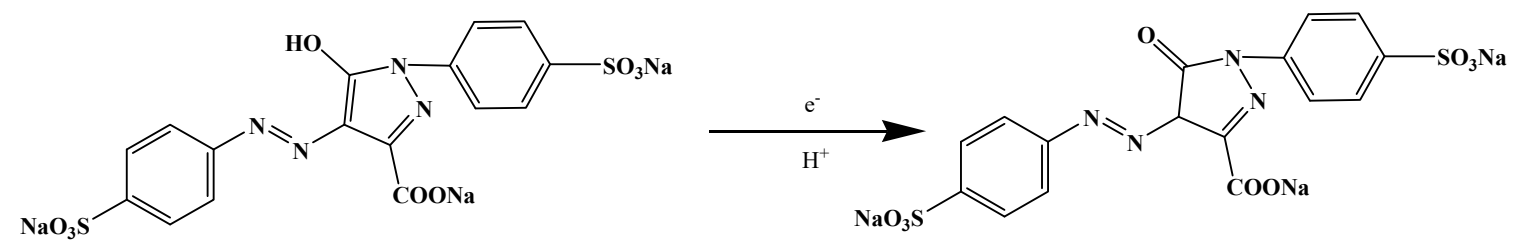

Scheme 1. The proposed reaction of tartrazine detection using electrochemical technique. The oxidation occurs at $1.1 \mathrm{~V}$ under optimized condition. 


\subsection{Dependence of Biosensor Response on $\mathrm{pH}$ and Exposure Time}

The oxidation behaviours of tartrazine in buffer solutions with different $\mathrm{pH}$ values were studied to discuss the influences of $\mathrm{pH}$ value. As seen in Figure 2, the oxidation peak currents of Tartrazine on microspheres-laccase/AuNPs/SPE were gradually increased with $\mathrm{pH}$ value from 2.0 to 5.0, and then gradually decreased with further $\mathrm{pH}$ until $\mathrm{pH}$ 8. To obtain higher response signals, $0.1 \mathrm{M}$ phosphate buffer with $\mathrm{pH}$ of 5.0 was used for the detection of tartrazine.

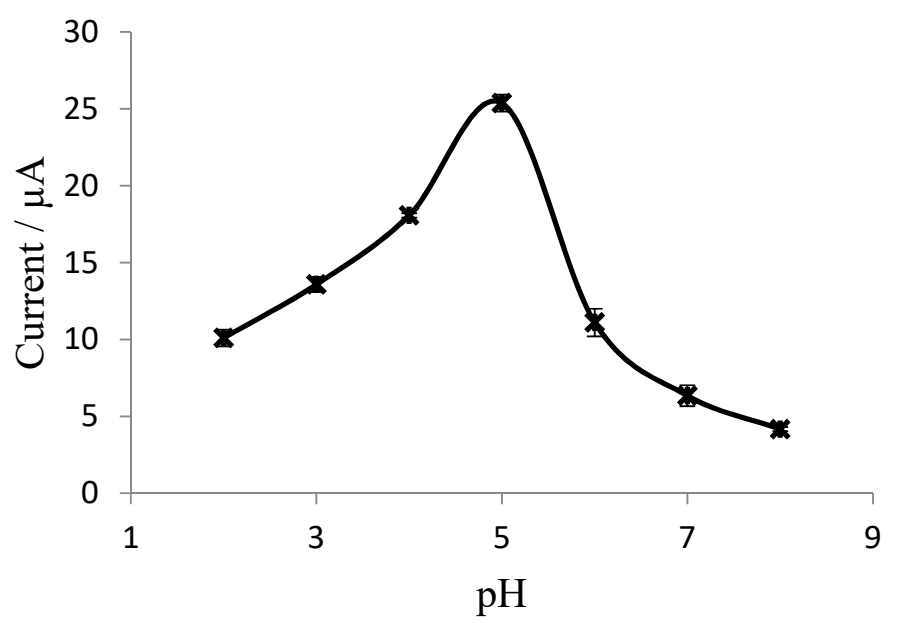

Figure 2. The effect of $\mathrm{pH}$ on the anodic peak potentials in $0.5 \mu \mathrm{M}$ Tartrazine solution on microspheres-laccase/AuNPs/SPE. Exposure time: 2 min. Error bar represents the standard deviation of triple measurements.

Figure 3 demonstrates the influences of exposure time of the electrode on the oxidation peak currents of Tartrazine. By extending the exposure time from 0 to $2 \mathrm{~min}$, the signals of Tartrazine oxidation increased significantly, indicating that suitable exposure time had improved the detection sensitivity. However, their oxidation signals decreased again when the exposure time was longer than $2 \mathrm{~min}$, which can probably be attributed to the deterioration of laccase and tartrazine reaction.

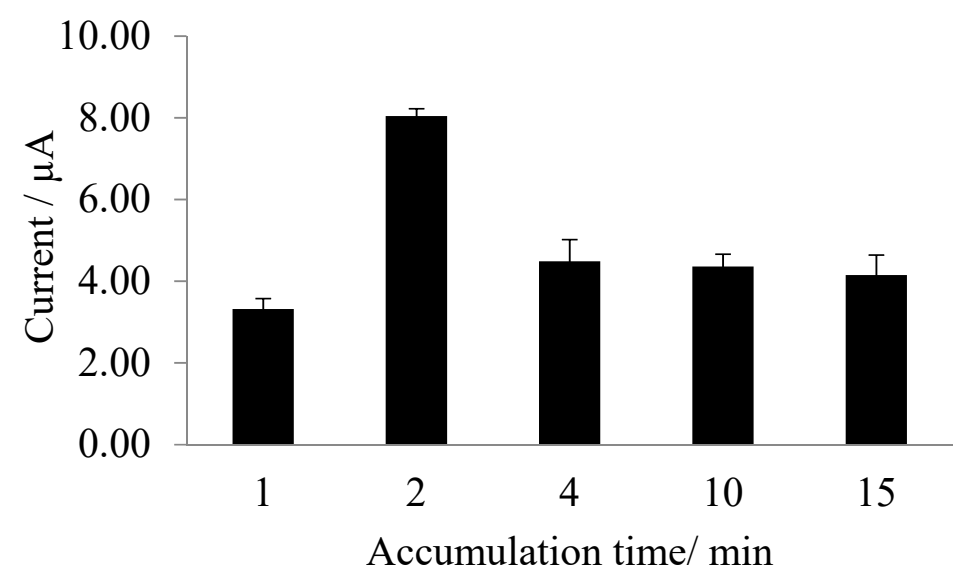

Figure 3. Effects of the exposure time on the oxidation peak current in the presence of $0.5 \mu \mathrm{M}$ Tartrazine in $0.1 \mathrm{M}$ PBS pH 5.0. Scan rate: $0.07 \mathrm{~V} / \mathrm{s}$. Error bar represents the standard deviation of triple measurements. 


\subsection{Effect of Microspheres and Nanogold Loading on Enzyme Biosensor Response}

The influence of methacrylate-acrylate microspheres on the voltammetry response of Tartrazine was explored. Results showed that the peak current increased quickly by increasing the amount of methacrylate-acrylate microspheres and reached the maximum response at $0.1 \mathrm{mg}$ (Figure $4 \mathrm{a}$ ), then further addition of methacrylate-acrylate microspheres caused a gradual decrease. The thickness of the working electrode will obviously increase the interface electron transfer resistance. Therefore, $0.1 \mathrm{mg}$ of methacrylate-acrylate microspheres was adopted for further study.
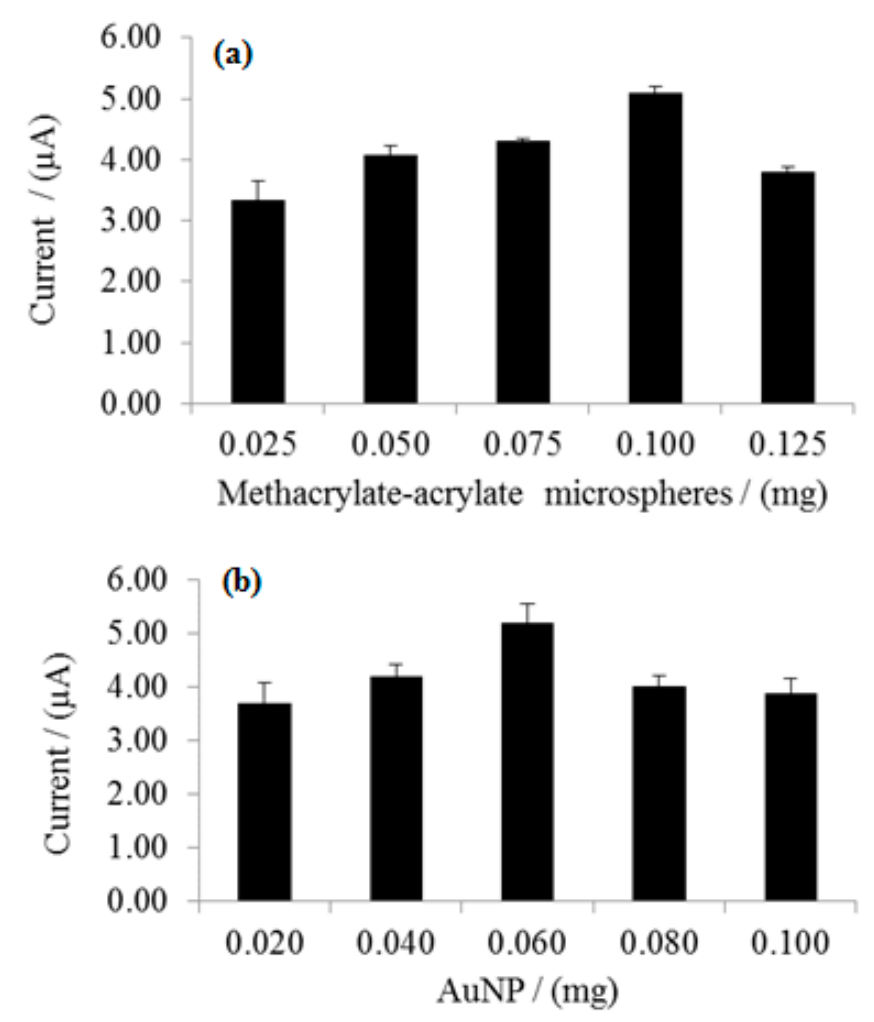

Figure 4. Anodic peak currents of $0.5 \mu \mathrm{M}$ Tartrazine on the surface of modified electrode with various amounts of (a) methacrylate-acrylate microspheres and (b) quantity of AuNPs. Error bar represents the standard deviation of triple measurements.

AuNPs have significantly contributed in amplifying the response of tartrazine oxidation as shown in Figure $4 \mathrm{~b}$. When gradually increasing the amount of AuNPs from 0.020 to $0.060 \mathrm{mg}$, the oxidation peak currents of tartrazine enhance greatly; this is attributable to the electron transfer ability being improved. When more AuNPs were added, signals were decreased, possibly due to the electrode surface being covered by AuNPs. Thus, the analyte had difficulties penetratrating to the enzyme active site. Hence, conductivity of the system decreased. So, the optimum amount of AuNPs was $0.060 \mathrm{mg}$.

\subsection{Influence of Laccase Immobilization Time}

Figure 5 shows a gradual increase of oxidation peak current from $1 \mathrm{~h}$ until $6 \mathrm{~h}$. It then achieved equilibrium after $6 \mathrm{~h}$. Longer immobilization time means more enzyme can attach with the microspheres. However, after optimum immobilization time $(6 \mathrm{~h})$, the signals were approximately stable, resulting from active sites of microspheres presumably being fully attached with laccase. 


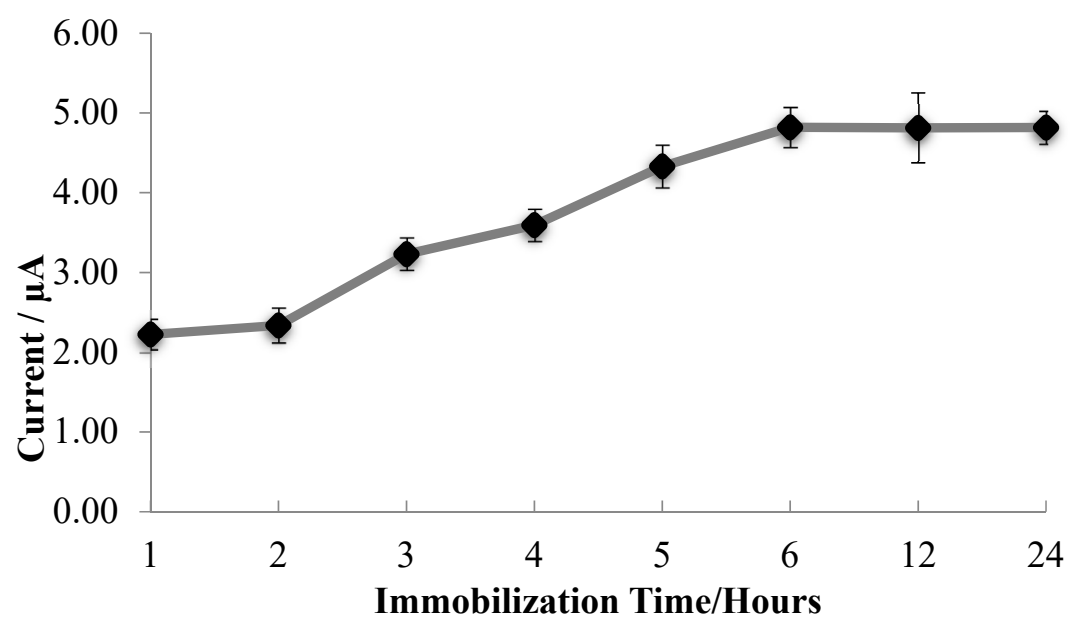

Figure 5. Influence of the laccase immobilization time on the anodic peak currents of $0.5 \mu \mathrm{M}$ Tartrazine. Error bar represents the standard deviation of triple measurements.

\subsection{Linear Range and Detection Limit of Tartrazine Biosensor}

Electrochemical response of tartrazine on microspheres-laccase/AuNPs/SPE was examined using DPV in $\mathrm{pH} 5.0$ phosphate buffer solution under the optimized experimental conditions. As shown in Figure 6, it is found that the oxidation current increased linearly with tartrazine concentration. The calibration curve of tartrazine response is $y=0.5172 x+1.3974$ with correlation coefficient $R^{2}=0.9799$ confirms good linearity and detection limit was $0.04 \mu \mathrm{M}(n=3)$.

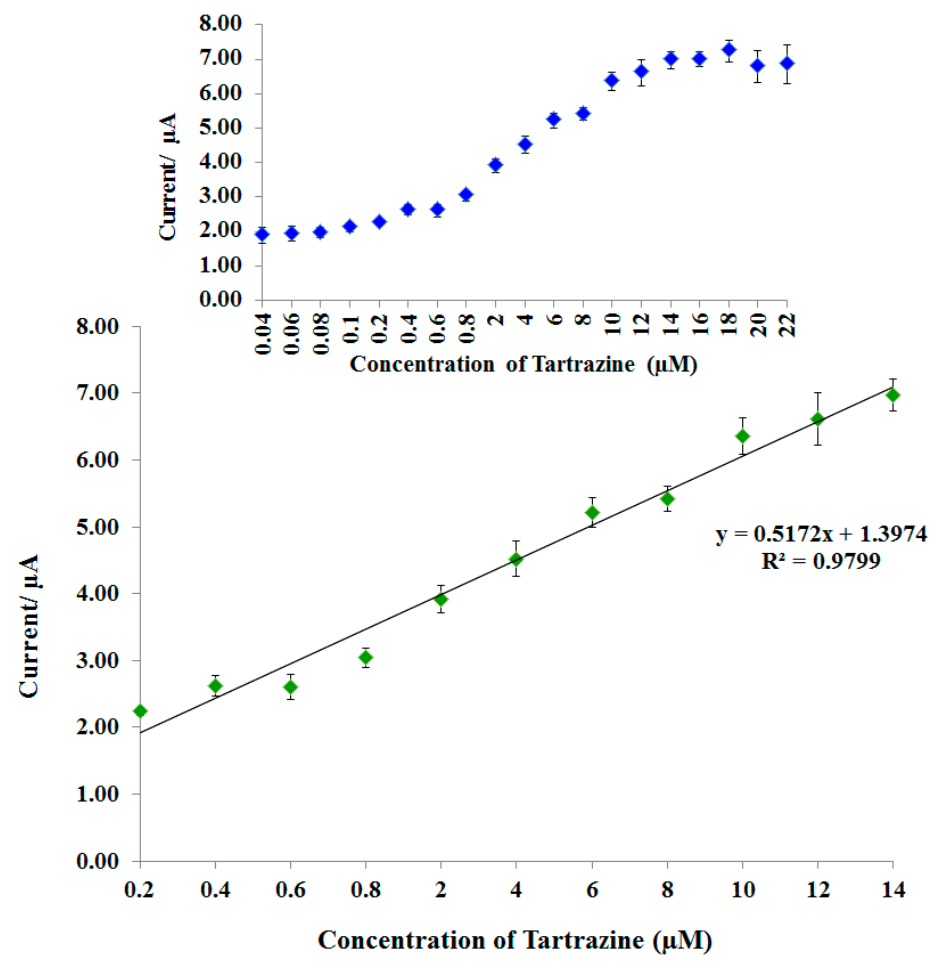

Figure 6. Calibration curve of the anodic peak currents as a function of Tartrazine concentrations in PBS (0.1 M, pH 5.0). Inset: Effect of concentration of Tartrazine solution. Accumulation time: $120 \mathrm{~s}$; Error bar represents the standard deviation of triple measurements.

The influence of common coexisting substances in tartrazine determinations, e.g., glucose, sucrose, ascorbic acid, phenol and the dye sunset yellow was investigated by DPV under optimized 
conditions. The microspheres-laccase/AuNPs electrode was evaluated by testing the electrochemical response of $0.5 \mu \mathrm{M}$ tartrazine in the presence of various ratios (1:0.01, 1:0.1, 1:1, 1:10, 1:100) of these substances. The tolerance limit was taken as the maximum concentration of these substances, which caused an approximately $\pm 10 \%$ relative error in the determination [6]. Peak currents showed small change below $\pm 10 \%$, which indicated that these substances had little interference effect on the microspheres-laccase/AuNPs/SPE based electrode and this confirmed a good biosensor selectivity as shown in Table 1. Most of laccase-based biosensors were developed for phenolic functionality at a different operating potential $0.8 \mathrm{~V}$. Thus, other phenolic compounds are not expected to interfere with tartrazine measurements.

Table 1. Percent of interfering substance in enzymatic biosensor.

\begin{tabular}{cccccc}
\hline \multirow{2}{*}{ Ratios } & \multicolumn{5}{c}{ Percent of Interference (\%) } \\
\cline { 2 - 6 } & Glucose & Sucrose & Ascorbic Acid & Phenol & Sunset Yellow \\
\hline $1: 0.01$ & -0.014 & 0.393 & 0.232 & -0.043 & -0.368 \\
$1: 0.1$ & 0.123 & 0.363 & 0.504 & 0.045 & 0.285 \\
$1: 1$ & 0.772 & 1.907 & 0.808 & 0.207 & 0.615 \\
$1: 10$ & 0.158 & 1.616 & 0.624 & 0.194 & 0.458 \\
$1: 100$ & 0.340 & 1.022 & -0.592 & -0.002 & 0.325 \\
\hline
\end{tabular}

To evaluate the reproducibility, five microspheres-laccase/AuNPs/SPE modified electrodes were prepared in the same way and $5.0 \mu \mathrm{M}$ and $0.08 \mu \mathrm{M}$ of tartrazine solution was determined. As a result, the relative standard deviation (RSD) of the peak current was $2.37 \%$ and $8.54 \%(n=5)$ respectively. The repeatability was investigated by monitoring a $5 \mu \mathrm{M}$ tartrazine solution using one electrode deposited with the functionalized polymer microspheres immobilized with laccase and the RSD of peak current was $86.30 \%(n=5)$. As expected due to a non-reversible reaction of tartrazine, the electrode cannot be reused and is identified as a disposable biosensor.

Moreover, storage stability was investigated by measuring a tartrazine solution intermittently for 90 days. After the sensor was stored for 10 days at $4{ }^{\circ} \mathrm{C}$, microspheres-laccase/AuNPs/SPE could retain $95.50 \%$ of tartrazine of its initial current response for $5.0 \mu \mathrm{M}$ of tartrazine solution. After one month-storage, the response still retained $81.33 \%$ of its initial current response. Finally, the biosensor response still retained $51.1 \%$ of the initial response after 90 days. Stability results for this biosensor were comparable with others laccase based biosensors [20,21]. The results reflected good reproducibility and stability of microspheres-laccase/AuNPs/SPE modified electrode suggesting acceptable storage stability.

\subsection{Validation of Tartrazine Biosensor in Food Samples}

Finally, the microspheres-laccase/AuNPs/SPE was applied to the determination of tartrazine in food and drink samples, specifically candy coated with chocolate and commercial mango juice. The percentage of recovery was between $94.75 \pm 5.10 \%$ and $108.00 \pm 4.88 \%(n=3)$ and the RSD was below $5 \%$. This suggested that the method had good accuracy and reliability thus confirming that the detection of tartrazine in real samples can be carried out. The response from the biosensor method was compared with the HPLC method [26]. Table 2 compares the results of the analysis. The results obtained using the biosensor method was in good agreement with the HPLC method indicating that the newly-developed sensing material is reliable and validated. 
Table 2. Determination of tartrazine in candy coated chocolate and commercial mango juice samples by microspheres-laccase/AuNPs/SPE modified electrodes $(n=3)$.

\begin{tabular}{ccccc}
\hline Samples & Spiked $(\mu \mathbf{M})$ & Biosensor $(\mu \mathbf{M})$ & HPLC $(\mu \mathbf{M})$ & Recovery $(\%)$ \\
\hline \multirow{2}{*}{ Candy coated } & 2 & 2.16 & 2.07 & 108.00 \\
with chocolate & 4 & 3.79 & 3.93 & 94.75 \\
& 6 & 6.11 & 6.03 & 101.83 \\
\hline \multirow{2}{*}{ Commercial } & 2 & 1.91 & 1.86 & 95.50 \\
mango juice & 4 & 4.09 & 4.12 & 102.25 \\
& 6 & 5.87 & 6.06 & 97.83 \\
\hline
\end{tabular}

Statistical analysis was performed to determine whether the developed method biosensor are correlated or not. These results showed that the biosensor method has a good correlation with the HPLC method with slopes of 0.9958 and 1.0577 respectively for candy coated with chocolate and commercial mango juice. In addition, $R^{2}$ values 0.9958 and 0.9998 were obtained for both samples. The statistical comparisons of the obtained values by these methods for the determination of tartrazine were analyzed by student's $t$-test. As can be seen from Table 2, the experimental $t$-values at $p=0.05$ for both techniques did not exceed the theoretical ones. The results confirmed that the response measures by the biosensor method and the HPLC method were not different.

In comparison to many reported electrochemical sensors without using enzyme, the selectivity of the bioelectrode developed here towards tartrazine is much improved as many of the reported electrochemical sensors could not determine tartrazine alone when another dye sunset yellow is present. These chemical sensors would determine both of these food dyes together [27-29]. Apart from demonstrating the advantage on a good selectivity towards tartrazine, the biosensor developed here also shows similar response range $(0.2$ to $14 \mu \mathrm{M})$ when compared to electrochemical sensors reported for tartrazine $[30,31]$.

\section{Conclusions}

A new electrochemical enzymatic biosensor based on laccase enzyme for tartrazine analysis was successfully developed. This new biosensor for tartrazine was fabricated from the immobilization of laccase on methacrylate-acrylate microspheres and composite with AuNPs, which then coated onto a SPE. A significant increase in the biosensor response upon detection of tartrazine was observed at $1.1 \mathrm{~V}$ and the signal was enhanced in the presence of gold nanoparticles (AuNPs). Furthermore, the modified electrode benefited wide linear range from $0.2 \mu \mathrm{M}$ to $0.10 \mu \mathrm{M}\left(R^{2}=0.979\right)$ and the limit of detection (LOD) of $0.04 \mu \mathrm{M}$. Although the operation potential of the biosensor was at the high end, there was no significant interference to biosensor response observed from possible interference species or when applied to the analysis of tartrazine in real food samples. Thus, the biosensor demonstrated good selectivity towards tartrazine analyte. The biosensor was characterized by a relatively fast response in two minutes and it showed excellent selectivity for tartrazine determination in real samples.

Supplementary Materials: The following are available online at www.mdpi.com/1424-8220/17/12/2859/s1, Figure S1: Chemical structure of tartrazine, Figure S2: SEM micrographs of polyGMA (A), polynBA (B), GN91 copolymer (C), GN82 copolymer (D) at $2.00 \mathrm{~K}$ magnification and (E) Size distribution of poly(GMA-co-nBA) microspheres in various composition.

Acknowledgments: This work was financially supported in part by Research Grants FRGS/1/2016/TK07/ UKM/02/02 and GUP-2016-061 given by Ministry of Higher Education and Universiti Kebangsaan Malaysia. Special thanks also to the Research and Instrumentation Management Center (CRIM), Universiti Kebangsaan Malaysia and Mohamad Nasir Mat Arip from Forest Research Institute Malaysia (FRIM) for the research facility.

Author Contributions: Siti Zulaikha Mazlan and Sharina Abu Hanifah conceived and designed the experiments; Siti Zulaikha Mazlan performed the experiments, analyzed the data and drafted the manuscript; Sharina Abu Hanifah and Yook Heng Lee contributed reagents/materials/analysis tools. All authors discussed the results and commented on the manuscript.

Conflicts of Interest: The authors declare no conflict of interest. 


\section{References}

1. Minussi, R.C.; Pastore, G.M.; Durán, N. Potential applications of laccase in the food industry. Trends Food Sci. Technol. 2002, 13, 205-216. [CrossRef]

2. Wang, M.; Zhao, J. Facile synthesis of Au supported on ionic liquid functionalized reduced graphene oxide for simultaneous determination of sunset yellow and tartrazine in drinks. Sens. Actuators B Chem. 2015, 216, 578-585. [CrossRef]

3. Zalacain, A.; Ordoudi, S.; Blazquez, I.; Díaz-Plaza, E.M.; Carmona, M.; Tsimidou, M.; Alonso, G. Screening method for the detection of artificial colours in saffron using derivative UV-Vis spectrometry after precipitation of crocetin. Food Addit. Contam. 2005, 22, 607-615. [CrossRef] [PubMed]

4. Yoshioka, N.; Ichihashi, K. Determination of 40 synthetic food colors in drinks and candies by high-performance liquid chromatography using a short column with photodiode array detection. Talanta 2008, 74, 1408-1413. [CrossRef] [PubMed]

5. Feng, F.; Zhao, Y.; Yong, W.; Sun, L.; Jiang, G.; Chu, X. Highly sensitive and accurate screening of 40 dyes in soft drinks by liquid chromatography-electrospray tandem mass spectrometry. J. Chromatogr. B 2011, 879, 1813-1818. [CrossRef] [PubMed]

6. Rodríguez-Delgado, M.M.; Alemán-Nava, G.S.; Rodríguez-Delgado, J.M.; Dieck-Assad, G.; Martínez-Chapa, S.O.; Barceló, D.; Parra, R. Laccase-based biosensors for detection of phenolic compounds. TrAC Trends Anal. Chem. 2015, 74, 21-45. [CrossRef]

7. Ling, Y.P.; Heng, L.Y. A potentiometric formaldehyde biosensor based on immobilization of alcohol oxidase on acryloxysuccinimide-modified acrylic microspheres. Sensors 2010, 10, 9963-9981. [CrossRef] [PubMed]

8. Hanifah, S.A.; Hamzah, N.; Lee, Y.H. Rapid synthesis of magnetic microspheres poly (Glycidyl Methacrylate-co-Styrene) by photopolymerization. Sains Malays. 2013, 42, 487-493.

9. Bayramoğlu, G.; Kiralp, S.; Yilmaz, M.; Toppare, L.; Arıca, M.Y. Covalent immobilization of chloroperoxidase onto magnetic beads: Catalytic properties and stability. Biochem. Eng. J. 2008, 38, 180-188. [CrossRef]

10. Danisman, T.; Tan, S.; Kacar, Y.; Ergene, A. Covalent immobilization of invertase on microporous pHEMA-GMA membrane. Food Chem. 2004, 85, 461-466. [CrossRef]

11. Brady, D.; Jordaan, J. Advances in enzyme immobilisation. Biotechnol. Lett. 2009, 31, 1639. [CrossRef] [PubMed]

12. Li, C.; Lou, Y.; Wan, Y.; Wang, W.; Yao, J.; Zhang, B. Laccase immobilized onto poly (GMA-MAA) microspheres for p-benzenediol removal from wastewater. Water Sci. Technol. 2013, 67, 2287-2293. [CrossRef] [PubMed]

13. Doğan, T.; Bayram, E.; Uzun, L.; Şenel, S.; Denizli, A. Trametes versicolor laccase immobilized poly (glycidyl methacrylate) based cryogels for phenol degradation from aqueous media. J. Appl. Polym. Sci. 2015. [CrossRef]

14. Mao, Y.; Fan, Q.; Li, J.; Yu, L.; Qu, L.-B. A novel and green CTAB-functionalized graphene nanosheets electrochemical sensor for Sudan I determination. Sens. Actuators B Chem. 2014, 203, 759-765. [CrossRef]

15. Gan, T.; Sun, J.; Cao, S.; Gao, F.; Zhang, Y.; Yang, Y. One-step electrochemical approach for the preparation of graphene wrapped-phosphotungstic acid hybrid and its application for simultaneous determination of sunset yellow and tartrazine. Electrochim. Acta 2012, 74, 151-157. [CrossRef]

16. Huang, H.-Y.; Shih, Y.-C.; Chen, Y.-C. Determining eight colorants in milk beverages by capillary electrophoresis. J. Chromatogr. A 2002, 959, 317-325. [CrossRef]

17. Karim-Nezhad, G.; Khorablou, Z.; Zamani, M.; Dorraji, P.S.; Alamgholiloo, M. Voltammetric sensor for tartrazine determination in soft drinks using poly (p-aminobenzenesulfonic acid)/zinc oxide nanoparticles in carbon paste electrode. J. Food Drug Anal. 2017, 25, 293-301. [CrossRef] [PubMed]

18. Mazlan, S.Z.; Hanifah, S.A. Synthesis and effect of modification on methacylate-acrylate microspheres for Trametes versicolor laccase enzyme immobilization. AIP Conf. Proc. 2014, 1, 263-268.

19. Mazlan, S.Z.; Hanifah, S.A. Effects of Temperature and $\mathrm{pH}$ on Immobilized Laccase Activity in Conjugated Methacrylate-Acrylate Microspheres. Int. J. Polym. Sci. 2017, 2017, 8. [CrossRef]

20. Fu, J.; Qiao, H.; Li, D.; Luo, L.; Chen, K.; Wei, Q. Laccase Biosensor Based on Electrospun Copper/Carbon Composite Nanofibers for Catechol Detection. Sensors 2014, 14, 3543-3556. [CrossRef] [PubMed] 
21. Dai, Z.; Guo, M.Q.; Wang, X.J.; Wang, H.F.; Chen, W.Y. Development of Amperometric Laccase Biosensor through Immobilizing Enzyme in Magnesium-Containing Mesoporous Silica Sieve (Mg-MCM-41)/Polyvinyl Alcohol Matrix. J. Nanomater. 2014, 2014, 8. [CrossRef]

22. Alves, S.P.; Brum, D.M.; de Andrade, É.C.B.; Netto, A.D.P. Determination of synthetic dyes in selected foodstuffs by high performance liquid chromatography with UV-DAD detection. Food Chem. 2008, 107, 489-496. [CrossRef]

23. Ulianas, A.; Heng, L.Y.; Ahmad, M. A biosensor for urea from succinimide-modified acrylic microspheres based on reflectance transduction. Sensors 2011, 11, 8323-8338. [CrossRef] [PubMed]

24. Freire, R.S.; Pessoa, C.A.; Mello, L.D.; Kubota, L.T. Direct electron transfer: An approach for electrochemical biosensors with higher selectivity and sensitivity. J. Braz. Chem. Soc. 2003, 14, 230-243. [CrossRef]

25. Rhieu, S.Y.; Reipa, V. Tuning the size of gold nanoparticles with repetitive oxidation-reduction cycles. Am. J. Nanomater. 2015, 3, 15-21. [CrossRef]

26. Ghoreishi, S.M.; Behpour, M.; Golestaneh, M. Simultaneous determination of sunset yellow and tartrazine in soft drinks using gold nanoparticles carbon paste electrode. Food Chem. 2012, 132, 637-641. [CrossRef] [PubMed]

27. Dorraji, P.S.; Jalali, F. Electrochemical fabrication of a novel ZnO/cysteic acid nanocomposite modified electrode and its application to simultaneous determination of sunset yellow and tartrazine. Food Chem. 2017, 227, 73-77. [CrossRef] [PubMed]

28. Ji, L.; Cheng, Q.; Wu, K.; Yang, X. Cu-BTC frameworks-based electrochemical sensing platform for rapid and simple determination of Sunset yellow and Tartrazine. Sens. Actuators B Chem. 2016, 231, 12-17. [CrossRef]

29. Deng, K.; Li, C.; Li, X.; Huang, H. Simultaneous detection of sunset yellow and tartrazine using the nanohybrid of gold nanorods decorated graphene oxide. J. Electroanal. Chem. 2016, 780, 296-302. [CrossRef]

30. Arvand, M.; Gaskarmahalleh, A.A.; Hemmati, S. Enhanced-Oxidation and Highly Sensitive Detection of Tartrazine in Foodstuffs via New Platform Based on Poly (5-Sulfosalicylic Acid)/Cu(OH $)_{2}$ Nanoparticles. Food Anal. Methods 2017, 10, 1-11. [CrossRef]

31. Wang, Z.; Shan, Y.; Xu, L.; Wu, G.; Lu, X. Development and application of the tartrazine voltammetric sensors based on molecularly imprinted polymers. Int. J. Polym. Anal. Charact. 2017, 22, 83-91. [CrossRef]

(C) 2017 by the authors. Licensee MDPI, Basel, Switzerland. This article is an open access article distributed under the terms and conditions of the Creative Commons Attribution (CC BY) license (http:/ / creativecommons.org/licenses/by/4.0/). 